\title{
Galloylated proanthocyanidins from shea (Vitellaria paradoxa) meal have potent anthelmintic activity against Ascaris suum
}

Article

Accepted Version

Ramsay, A., Williams, A., Thamsborg, S. and Mueller-Harvey, I. (2016) Galloylated proanthocyanidins from shea (Vitellaria paradoxa) meal have potent anthelmintic activity against Ascaris suum. Phytochemistry, 122. pp. 146-153. ISSN 00319422 doi: https://doi.org/10.1016/j.phytochem.2015.12.005 Available at https://centaur.reading.ac.uk/49230/

It is advisable to refer to the publisher's version if you intend to cite from the work. See Guidance on citing.

To link to this article DOI: http://dx.doi.org/10.1016/j.phytochem.2015.12.005

Publisher: Elsevier

All outputs in CentAUR are protected by Intellectual Property Rights law, including copyright law. Copyright and IPR is retained by the creators or other copyright holders. Terms and conditions for use of this material are defined in the End User Agreement.

www.reading.ac.uk/centaur 
Central Archive at the University of Reading

Reading's research outputs online 
Galloylated proanthocyanidins from shea (Vitellaria paradoxa) meal have potent anthelmintic activity against Ascaris suum

A. Ramsaya ${ }^{a}$, A. R. Williams ${ }^{b}$, S. M. Thamsborg ${ }^{b}$, I. Mueller-Harvey ${ }^{a}$

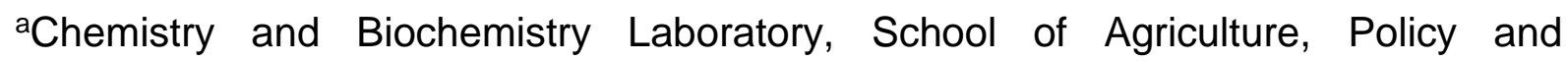
Development, University of Reading, 1 Earley Gate, P O Box 236, Reading RG6 6AT, U.K.

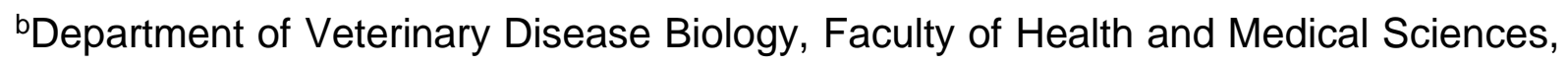
University of Copenhagen, Frederiksberg, Denmark.

*Corresponding author: aina.ramsay@reading.ac.uk, aina.ramsay@hotmail.fr 


\section{ABSTRACT}

Proanthocyanidins (PA) from shea (Vitellaria paradoxa) meal were investigated by thiolytic degradation with benzyl mercaptan and the reaction products were analysed by high performance liquid chromatography - mass spectrometry. These PA were highly galloylated $(\approx 40 \%)$, contained only B-type linkages and had a high proportion of prodelphinidins $(>70 \%)$. The mean degree of polymerisation was 8 (i.e. average molecular size was 2384 Daltons) and epigallocatechin gallate (EGCg) was the major flavan-3-ol subunit in PA. Shea meal also proved to be a potentially valuable source for extracting free flavan-3-ol-O-gallates, especially EGCg $(575 \mathrm{mg} / \mathrm{kg}$ meal), which is known for its health and anti-parasitic benefits. Proanthocyanidins were isolated and tested for bioactivity against Ascaris suum, which is an important parasite of pigs. Migration and motility tests revealed that these PA have potent activity against this parasitic nematode.

Keywords: shea meal, Vitellaria paradoxa (Sapotaceae), thiolysis, proanthocyanidins, galloylated, Ascaris suum, anthelmintic, LC-MS 


\section{Introduction}

Vitellaria paradoxa is a tropical tree that yields nuts for use in cooking and for producing shea butter, which is an important cosmetic product (Hall et al., 1996; Zhang et al., 2014; website 1). Shea meal is the residue that remains after lipid extraction. Currently the meal is an agro-industrial by-product and has been investigated as an environmentally friendly fuel (Dei et al., 2007; Munir et al., 2009; Munir et al., 2010). However, an important policy objective of many governments nowadays is to move towards a low carbon economy and this requires information on how to add value to such agro-industrial 'waste' products (website 2).

Several studies noted that shea meal, despite its high protein content, has a low nutritive value for poultry due to saponins and tannins, and that the anti-nutritional effects can be reduced, but not removed, by fermentation or boiling with water (Atuathene et al., 1998; Dei et al., 2007 and 2008). The current evidence suggests that shea meal has some, albeit very limited, potential as a feed supplement (Ansah et al., 2011).

The total harvest of shea nuts in West Africa ranges from 100,000 to 600,000 tons per year (Dei et al., 2007 and 2008; website 1); approximately 50,000 tons were exported in 1997 with a value of 10 million US \$. Fat accounts for half of the nut weight, which means that large volumes of shea press cake or shea meal are produced, but this by-product has a very low value (Dei et al., 2007). Therefore, a better understanding of its chemical composition might help to add value to this material.

A detailed survey of shea kernels from different $V$. paradoxa accessions in several African countries found that nuts contained terpenoids, steroids, flavonoids (including catechin and epicatechin), gallic acid, and cinnamic acid (Maranz et al., 2003; Zhang 
et al., 2014) and the resulting shea meal contained variable quantities of protein, fibre, ash, minerals, saponins, tannins and theobromine (Dei et al., 2007). Although the presence of tannins has been reported (Dei et al., 2007; website 1), their structures have not yet been characterised.

Proanthocyanidins (PA) are poorly bioavailable and thus able to exert their bioactivity in the gastrointestinal tract, where they can impact positively on macrofauna, microflora and host immunity (Bancroft et al., 2012). There is considerable interest in the anti-parasitic effects of PA (Hoste et al., 2012); however, the potential effects of shea meal tannins on gastrointestinal pathogens such as parasitic nematodes have not yet been investigated. Due to the rising threat of drug resistance against helminth parasites, and the high cost of drug treatment in some countries, dietary supplements containing natural anti-parasitic compounds have been proposed as a sustainable control measure (Hoste et al., 2015).

Here, we report for the first time the isolation and identification of condensed tannins or proanthocyanidins (PA) and also the presence of several different flavan-3-ol monomers from shea meal. We then tested the anthelmintic activity of isolated PA fractions against Ascaris suum, which is a highly prevalent gastrointestinal parasite of pigs worldwide, and has been reported to significantly reduce growth and performance (Hale et al., 1985, Vlaminck et al., 2015).

\section{Results and Discussion}

\subsection{Identification of proanthocyanidins in shea meal}

The constituent flavan-3-ols of shea PA were identified by thiolytic degradation (Gea et al., 2011). Thiolysis was applied to acetone/water extractable PA, to unextractable PA that remained in the residue after extraction and also directly to the whole meal 
(in situ PA). The thiolysis reaction released the terminal units as flavan-3-ols and the extension units as benzyl mercaptan (BM) derivatives, which can be analysed by reversed-phase HPLC-ESI-MS.

The sum of extractable PA (3.1 g/100 g dry weight (DW)) plus unextractable PA (2.1 $\mathrm{g} / 100 \mathrm{~g} \mathrm{DW}$ ) gave a total PA content of $5.2 \mathrm{~g} / 100 \mathrm{~g}$ dry weight for shea meal (Table 1). However, direct in situ analysis of the shea meal yielded only $3.9 \mathrm{~g} \mathrm{PA} / 100 \mathrm{~g}$ DW. This suggests that the direct thiolysis method, which had been developed for sainfoin PA (Gea et al., 2011), would require optimisation for shea meal PA. It may also indicate that the matrix can interfere with the thiolysis reaction or that aqueous acetone treatment can enhance the accessibility of PA to benzyl mercaptan. Extractable PA had a lower mean degree of polymerisation (mDP) than unextractable PA (i.e. 4.0 vs 13.8), but a higher percentage of prodelphinidins (i.e. 73.4 vs 65.9) as observed previously in sainfoin (Gea et al., 2011). In situ PA, extractable PA and unextractable PA differed significantly in PA contents, mDP, percentage of PC or PD, percentage of cis- or trans-flavan-3-ols and also in the extent of galloylation ( $P$ $<0.001)$ (Table 1).

\subsubsection{Flavan-3-ol composition of proanthocyanidins}

EGCg was the major terminal unit and GC the major extension unit (Table 2). Chromatographic analysis by LC-MS revealed the presence of several galloylated flavan-3-ol subunits, which were assigned by MS and by comparison with authentic standards. Prodelphinidin (PD) subunits, i.e. GC and EGC, and procyanidin (PC) subunits, i.e. C and EC, were detected as galloylated (g) and as non-galloylated flavan-3-ols (Table 2). Most of the flavan-3-ol compositions differed significantly between the in situ, extractable and unextractable PA $(P<0.001)$; and only few of the 
flavan-3-ol subunit percentages were the same, e.g. EGCg and Cg extension units of extractable and unextractable PA; ECg terminal and extension units of in situ and extractable PA; and GC and EGC and $\mathrm{Cg}$ extension units of in situ and residual PA. These findings may point to the contributions these flavan-3-ols make towards the solubility or unextractability of the PA in $70 \%$ aqueous acetone.

Galloylated flavan-3-ol units accounted for $37.7 \%$ and $31.6 \%$ of the total flavan-3-ols in extractable and unextractable PA, respectively (Table 1). This represents a high degree of galloylation in comparison to the galloylated PA of grapeseeds $(<10 \%)$ (Meagher et al., 2005) but is lower than the highly galloylated persimmon PA (72\%) (Li et al., 2010). These PA are unusual not only because of their relatively high degree of galloylation but also because of their high GC contents (>20\%), as cisflavan-3-ols, e.g. EGC or EC, tend to be the most common extension units (Porter, 1988).

\subsection{Other compounds}

Significantly different concentrations of free flavan-3-ol monomers were identified in the whole meal and extract $(P<0.005)$; i.e. galloylated flavan-3-ols $(\mathrm{GCg}, \mathrm{EGCg}$ and $\mathrm{ECg}$ ) were detectable in the meal, and both galloylated and non-galloylated flavan-3ols were found in the extract (GCg, EGCg, ECg, GC, EGC and EC) (Table 3). EGCg was the major flavan-3-ol monomer and accounted for $2.3 \mathrm{~g} / 100 \mathrm{~g}$ of the extract. Gallic acid was also detected in the meal and extract but not quantified. The presence of flavan-3-ols and gallic acid is in agreement with the literature (Maranz et al., 2003; Zhang et al., 2014). However, quercetin, cinnamic acid, theobromine or saponins were not detected in the meal, as these compounds had probably been coextracted with lipids during the processing of shea nuts, or it could be a matter of 
variation between accessions or provenances (Atuathene et al., 1998).

\subsection{Characterisation of the PA fractions from shea meal}

\subsubsection{Analysis of PA-fractions by thiolytic degradation}

Sephadex LH-20 was used to obtain three PA fractions from the aqueous acetone extract in order to test their efficacy against $A$. suum. With most plant materials, this fractionation scheme removes impurities and generates highly pure PA, especially for the F2-fraction, and also yields fractions with different mDP values, which is of particular interest for anthelmintic analysis when assessing their bioactivities (Novobilský et al., 2011; Williams et al., 2014; Quijada et al., 2015). The PA content and overall composition is described in Table 4 and the molar percentages of individual flavan-3-ol subunits within the PA fractions in Table 5 (see also Supplementary Section). Figure 2 illustrates the HPLC chromatogram of the thiolysed F2-fraction. The PA contents ranged from 33 to 45 ( $\mathrm{g} / 100 \mathrm{~g}$ fraction) and consisted mostly of prodelphinidins ( $>72 \%$ ). As expected, the mDP increased from 2.2 to $7.7 \mathrm{in}$ line with the acetone content that was used to elute these F1-, F2- and F3-fractions (Williams et al., 2014).

The F2-fraction had the highest PA content $(P<0.001)$ and most of the flavan-3-ol compositions of the three fractions were also significantly different (Table 4; $P$ $<0.001$; Table 5, $P<0.009$ ). However, apart from the increase in mDP-values, there were no other trends; e.g. the percentage of galloylated subunits $(\mathrm{Xg})$ ranged from 29, 46 and $38 \%$ in the F1-, F2- and F3-fractions. Given our previous observations we had expected that PA contents would increase in line with the acetone content (Zeller et al., 2015). However, shea meal appears to contain non-PA impurities (see Section 2.3.2) that were eluted by $50 \%$ aqueous acetone and this explains the relatively low 
PA content of the F2-fraction. It is also worth pointing out also that galloylation has a profound effect on flavan-3-ol and PA solubilities (Mueller-Harvey, 2006) and influences their ability to interact with other compounds (Dobreva et al., 2014; Frazier et al 2010), which may have contributed to these surprisingly similar contents and compositions.

Several free flavan-3-ol monomers were also detected in two of the fractions (Table 3). The F1-fraction contained both galloylated and non-galloylated flavan-3-ols, with GC, EGCg and EGC being the major ones. The F2-fraction contained only galloylated flavan-3-ols with EGCg being the major one. No free flavan-3-ol monomers were present in the F3-fraction.

\subsubsection{NMR analysis of F2-fraction}

The F2-fraction had the highest PA content (45 g/100 fraction) and was subjected to NMR (HSQC) (Grabber et al., 2013; Zeller et al., 2015) in order to assess the nature of the impurities and to check for any other tannins that might not have been detected by thiolysis. This suggested that the major impurities consisted of lipids, sugars and other phenolic compounds (i.e. ${ }^{1} \mathrm{H}$-signals between 0.5 and $3 \mathrm{ppm}$ and ${ }^{13} \mathrm{C}$-signals between 10 and $60 \mathrm{ppm}$ ); there was no evidence of A-type PA (Kamiya et al., 2001). Signal assignments for these PA are reported in Table S3 according to the numbering scheme illustrated in Figure 1.

The HSQC spectrum showed the presence of PC and PD tannins, where the signal at $6.57 \mathrm{ppm}$ is assignable to $\mathrm{H} / \mathrm{C}-2^{\prime}$ and $\mathrm{H} / \mathrm{C}-6^{\prime}(\mathrm{PD})$, at $6.75 \mathrm{ppm}$ to $\mathrm{H} / \mathrm{C}-5^{\prime}(\mathrm{PC})$, at $6.77 \mathrm{ppm}$ to $\mathrm{H} / \mathrm{C}-6^{\prime}$ (PC) and at $7.06 \mathrm{ppm}$ to $\mathrm{H} / \mathrm{C}-2^{\prime}$ (PC) (Grabber et al., 2013). The signal at $4.83 \mathrm{ppm}$ was assigned to $\mathrm{H}_{4}$ and at $6.00 \mathrm{ppm}$ to $\mathrm{H}_{6}$ and $\mathrm{H}_{8}$. Signals at 5.25 and $5.53 \mathrm{ppm}$ were assigned to $\mathrm{H} / \mathrm{C}-2$ and the fact that more than one signal was 
detected for $\mathrm{H}_{2}$ could be due to the stereochemistry, i.e. cis/trans configurations at the C-ring (Foo et al., 2000). The signal at 7.03 ppm was attributed to a galloyl group $(2 \mathrm{H})$ and was confirmed by comparison with authentic gallic acid.

\subsection{Anthelmintic activity of purified PA fractions from shea meal against $A$.}

\section{suum}

\subsubsection{Inhibition of Ascaris suum larval migration}

We assessed the biological activity of the shea PA fractions by measuring anthelmintic activity against the highly prevalent pig parasite, A. suum. Using a migration inhibition assay, we found that all three of the fractions were able to inhibit the migration of third-stage larvae (L3, i.e.the stage of the parasite that emerges from the egg after ingestion to infect the host). The effect of concentration was highly significant $(P<0.001$ by two-way ANOVA), indicating that all 3 fractions inhibited larval migration in a dose-dependent manner (Figure 3). We determined $\mathrm{EC}_{50}$ values (95\% $\mathrm{Cl})$ to be $64.1(47.5-87.5)$ for the F1-fraction, 55.1 (27.6-109.8) for the F2-fraction, and $64.3 \mu \mathrm{g}$ (53.5-77.3) for the F3-fraction (all concentrations are in $\mu \mathrm{g}$ fraction $/ \mathrm{ml}$ ). These concentrations of PA are expected to be biologically relevant. As previously discussed (Williams et al., 2014), a concentration of $1000 \mu \mathrm{g}$ of PA/ml in the porcine small intestine was expected to be achievable based on literature reports of the levels of PA in the diet that are readily consumed by pigs (Mitaru et al., 1984, Cousins et al., 1981), however precise measurements of locally available PA in the intestine following dietary consumption in pigs have not yet been performed.

There was no effect of fraction (F1, F2 or F3) on larval migration inhibition ( $P=0.59$ by two-way ANOVA), nor were there significant differences between $\mathrm{EC}_{50}$ values ( $P=0.658$ by extra sum-of-squares $F$-test) indicating that all 3 fractions had 
comparable anthelmintic activity despite some compositional differences. Although no adjustments were made for PA concentration, Table 4 shows that F1- and F3fractions have basically the same PA concentrations (33.0 vs $33.5 \mathrm{~g} / 100 \mathrm{~g}$ fraction), which means that here we can examine the effect of mDP or PA size. Proanthocyanidins in the F3-fraction had a higher mDP than in the F1-fraction (7.7 vs 2.2) but this did not give rise to a more potent anthelmintic effect. This result is in clear contrast to what had been recently observed with other PA types (Williams et al., 2014) and may indicate that, in the case of the highly galloylated shea PA, galloylation was an important contributor to anthelmintic activity rather than the average polymer size. In fact, previous studies (Brunet and Hoste, 2006; Molan et al., 2004; Molan et al., 2003) showed that flavan-3-ol monomers with $3 \mathrm{OH}$-groups in the B-ring (i.e. GC and EGC) and especially their galloylated derivatives were the most active flavan-3-ols in the larval exsheathment inhibition assay. The high percentage of prodelphinidins $(>75 \%)$ and extent of galloylation $(>29 \%)$ can, therefore, explain the potent anthelmintic activity of these shea meal PA.

Whilst a comparison of results between separate in vitro anthelmintic activity studies is problematic unless done in the same experiment, the shea F1-fraction proved more potent against L3 than other F1-fractions tested previously, which had been obtained from sainfoin plants, black or red currant leaves (Williams et al., 2014).

\subsubsection{Inhibition of motility of $A$. suum}

We next tested the fractions against fourth-stage larvae (L4), i.e. the stage of the parasite that arises following the moult from L3, which is present for a longer period in the small intestine and is continually exposed to the host digesta, thus presenting a more biologically relevant target for dietary anthelmintic compounds. Larvae were 
incubated in culture media with one of the fractions at each of three concentrations $(0.5,1$ and $2 \mathrm{mg} / \mathrm{ml})$. Similar to the L3 experiments, all 3 fractions showed potent inhibition of L4 motility within 12 hours of incubation (Figure 4). Within 36 hours most larvae were dead at all tested concentrations of all three fractions. Although, as stated above, caution is needed when comparing different studies, the F1- and F2fractions at $0.5 \mathrm{mg} / \mathrm{ml}$ were much more potent inhibitors of L4 larval motility than previously tested PA (Williams et al., 2014).

By assessing the time taken for larvae to register a motility score of zero, a significant dose-response curve was evident for Fraction $3(P=0.007)$ and a tendency for a dose-response curve for Fraction $1(P=0.07)$. However, no such dose relationship was evident for Fraction $2(P=0.9)$. To compare the potency of the different fractions, a similar analysis was performed only at the $0.5 \mathrm{mg} / \mathrm{ml}$ dose, as the higher concentrations were very potent for all three fractions. However, at the lower concentration, a difference was evident that tended to be significant $(P=0.051)$, reflecting a lower potency of the F3- compared to the F1- and F2- fractions.

Motility inhibition was also not related to the average PA polymer size (mDP), percentage of prodelphinidins or procyanidins or percentage of cis- or trans-flavan-3ols. The high activity against L3 and L4 larvae by these three PA fractions is likely to have been caused by the galloylated PA and possibly also by galloylated flavan-3-ol monomers.

\section{Conclusions}

To summarise, this study has shown that the agro-industrial by-product, which remains after lipid extraction of shea nuts, is an unusually rich source of galloylated flavan-3-ol monomers and highly galloylated proanthocyanidins. Given the results 
presented here, shea meal may have potential for promising applications as a nutraceutical anthelmintic feed for controlling Ascaris suum and possibly other pathogens (Hoste et al., 2015; Ogunwande et al., 2001). Shea meal could also provide a valuable and cost-effective alternative to imported, synthetic anthelmintic drugs in areas where shea nuts are harvested and where livestock production may be threatened by resistance to anthelmintic drugs (Sutherland et al., 2011).

It is important to recognise the difference between the tannin-containing plant approach that controls and the anthelmintic drug approach that eliminates parasites. Whilst the EC50-values of synthetic drugs such as ivermectin tend to be $25-50$ fold lower than the shea meal PA assessed here (A.R. Williams, unpublished data), the plant tannin approach does not seek to eliminate all parasites with a single therapeutic dose but serves instead as a nutraceutical, which keeps the parasite burden under a threshold where it causes little economic or health damage to the animal. This approach, therefore, can reduce reliance on drugs that requires less treatments and thus achieves lower cost to livestock owners and minimises opportunities for anthelmintic resistance to develop (Hoste et al., 2015).

\section{Experimental}

\subsection{General}

Acetone (analytical reagent grade), dichloromethane (HPLC grade) and acetonitrile (HPLC grade) were purchased from ThermoFisher Scientific Ltd (Loughborough, U.K.); ( \pm )-taxifolin (98\%) from Apin Chemicals (Abingdon, U.K.); benzyl mercaptan (99\%), catechin (C), epicatechin (EC), gallocatechin (GC), epigallocatechin (EGC), catechin-3-O-gallate $(\mathrm{Cg})$, epicatechin-3-O-gallate $(\mathrm{ECg})$, gallocatechin-3-O-gallate $(\mathrm{GCg})$, epigallocatechin-3-O-gallate (EGCg), from Sigma-Aldrich (Poole, U.K.). 
Sephadex ${ }^{\mathrm{TM}}$ LH-20 from GE Healthcare (Little Chalfont, UK). Deionised water was obtained from a Milli-Q System (Millipore, Watford, U.K.).

\subsection{Samples}

Defatted shea (Vitellaria paradoxa) meal was kindly provided by AarhusKarlshamm Sweden AB, Sweden and originated from nuts that had been sourced from Ghana.

\subsection{Extraction and purification}

\subsubsection{Preparation of extractable and unextractable proanthocyanidins}

Finely ground shea meal $(20.0 \mathrm{~g})$ was extracted three times for $1 \mathrm{~h}$ (each time) with acetone/water $(250 \mathrm{ml} \times 3 ; 7: 3 ; \mathrm{v} / \mathrm{v})$ at room temperature and filtered through a Buchner funnel. Acetone in the supernatant was removed under vacuum on a rotary evaporator at $30{ }^{\circ} \mathrm{C}$; the remaining aqueous solution was centrifuged for $3 \mathrm{~min}$ at 2045 x g (Jouan CR3i Multifunction Centrifuge, Thermo Electron Corporation, Basingstoke, UK) and freeze-dried (extract $=4.98 \mathrm{~g}$; yield $=25 \mathrm{~g}$ extract $/ 100 \mathrm{~g} \mathrm{DW}$ of meal). Acetone was also allowed to evaporate from the extracted shea meal residue in the fume cupboard before freeze-drying the residue prior to analysing unextractable PA.

\subsubsection{Purification of proanthocyanidins from shea meal}

Finely ground shea meal $(53 \mathrm{~g})$ was extracted as above $(1 \mathrm{~h} ; 250 \mathrm{ml} \times 3 ; 7: 3 ; \mathrm{v} / \mathrm{v})$ and the remaining aqueous solution was centrifuged for $3 \mathrm{~min}$ at $4364 \times \mathrm{g}$. The supernatant was dissolved in distilled water (2 I) and passed through a Sephadex LH-20 resin (50 g; GE Healthcare, Little Chalfont, U.K.), which had been conditioned with water. Distilled water was added to remove sugars and other impurities. The first 
fraction (F1-fraction) of proanthocyanidins was eluted with acetone/water (1 I; 3:7; $\mathrm{v} / \mathrm{v})$; the second fraction (F2-fraction) with acetone/water $(1 \mathrm{I} ; 1: 1 ; \mathrm{v} / \mathrm{v})$ and the third fraction (F3-fraction) with acetone/water (1 I; 7:3; v/v). Acetone was removed and the aqueous solutions were treated as above.

\subsection{Proanthocyanidin analysis}

\subsubsection{Thiolysis of extracted and fractionated proanthocyanidins}

The freeze-dried acetone/water extract or Sephadex $\mathrm{LH}-20$ fractions $(8 \mathrm{mg})$ were placed into a screw cap glass tube with a stirring magnet, methanol $(1.5 \mathrm{ml})$, methanol acidified with concentrated $\mathrm{HCl}(3.3 \% ; 500 \mu \mathrm{l})$ and benzyl mercaptan (50 $\mu \mathrm{l})$. The tubes were capped and placed into a water bath at $40^{\circ} \mathrm{C}$ for $1 \mathrm{~h}$ under vigorous stirring. Placing the tubes in an ice bath for 5 min stopped the reaction. Then distilled water $(2.5 \mathrm{ml})$ and internal standard, taxifolin in methanol $(500 \mu \mathrm{l} ; 0.1$ $\mathrm{mg} / \mathrm{ml}$ ), was added and thoroughly mixed. The mixture was transferred into a vial (0.8 ml; Chromacol 08-CPV; ThermoFisher Scientific Ltd), closed with a crimp top and analysed by liquid chromatography-mass spectrometry (LC-MS) within $24 \mathrm{~h}$.

\subsubsection{In situ thiolysis of proanthocyanidins in shea meal or residue}

Freeze-dried whole shea meal and also the residue $(250 \mathrm{mg})$, which remained after acetone/water extraction (see Section 4.3.1), was reacted with the thiolysis reagent $(2 \mathrm{ml}$ methanol, $1 \mathrm{ml}$ of $3.3 \% \mathrm{HCl}$ in methanol, and $100 \mu \mathrm{l}$ benzyl mercaptan) as above. After the reaction, methanol $(1 \mathrm{ml})$ was added to the mixture. The sample was mixed and centrifuged at $2727 \times \mathrm{g}$ for $3 \mathrm{~min}$, and supernatant $(1 \mathrm{ml})$ was transferred into another screw cap glass tube. Distilled water $(9 \mathrm{ml})$ was added to this supernatant. After thorough mixing, the solution was added to a pre-packed SPE mini-cartridge (C-18, 500 mg; 6 ml; Bond-Elute- $\mathrm{C}_{18}$; Agilent Technologies, U.K.), which had been conditioned with methanol and distilled water [Note: 
The in situ method (Gea et al., 2011) uses Sephadex LH-20 cartridges to remove impurities from the sainfoin plant matrix, but in the case of shea meal, the use of SPE cartridges were not essential but improved reproducibility (e.g. with SPE - $3.9 \mathrm{~g}$ PA/100 meal, without SPE: $4.0 \mathrm{~g} \mathrm{PA} / 100 \mathrm{~g}$ meal)]. Methanol (2.5 ml) was added to elute the thiolysis reaction products under gravity and the internal standard, taxifolin in methanol $(500 \mu \mathrm{l} ; 0.1 \mathrm{mg} / \mathrm{ml}$ ) was added to the collection tubes as described previously (Gea et al., 2011). The reaction products were analysed by LC-MS (see below). The concentrations of free flavan-3-ol monomers were also determined because they interfere with calculation of the mean degree of polymerisation, PA contents and composition (Gea et al., 2011). Free flavan-3-ols were measured directly in shea meal by LC-MS using the above 'thiolysis reagent' and reaction conditions for the extraction, where the $\mathrm{HCl}$-methanol $(1 \mathrm{ml})$ and benzyl mercaptan $(100 \mu \mathrm{l})$ reagents had been replaced with methanol $(1100 \mu \mathrm{l})$.

\subsubsection{Liquid chromatography-mass spectrometry (LC-MS) analysis}

Flavan-3-ols and their benzyl mercaptan (BM)-adducts were identified by LC-MS analysis on an Agilent 1100 Series HPLC system and an API-ES instrument Hewlett Packard 1100 MSD detector (Agilent Technologies, Waldbronn, Germany). Samples $(20 \mu \mathrm{l})$ were injected into the HPLC connected to an ACE $\mathrm{C}_{18}$ column $(3 \mu \mathrm{m} ; 250 \mathrm{x}$ $4.6 \mathrm{~mm}$; Hichrom Ltd, Theale, U.K.), which was fitted with a corresponding ACE guard column, at room temperature. The HPLC system consisted of a G1379A degasser, G1312A binary pump, G1313A ALS autoinjector, and G1314A VWD UV detector. Data were acquired with ChemStation software (version A 10.01 Rev. B.01.03). The flow rate was $0.75 \mathrm{ml} / \mathrm{min}$ using $1 \%$ acetic acid in water (solvent $\mathrm{A}$ ) and HPLC-grade acetonitrile (solvent B). The following gradient programme was employed: 0-35 min, 36\% B; 35-40 min, 36-50\% B; 40-45 min, 50-100\% B; 45-55 $\min , 100-0 \% \mathrm{~B} ; 55-60 \mathrm{~min}, 0 \% \mathrm{~B}$. Eluting compounds were recorded at $280 \mathrm{~nm}$. 
Mass spectra were recorded in the negative ionisation scan mode between $\mathrm{m} / \mathrm{z} 100$ and 1000 using the following conditions: capillary voltage, $-3000 \mathrm{~V}$; nebuliser gas pressure, $35 \mathrm{psi}$; drying gas, $12 \mathrm{ml} / \mathrm{min}$; and dry heater temperature, $350^{\circ} \mathrm{C}$. Terminal and extension units were identified by their retention times and their molecular masses. Peak areas of flavan-3-ol terminal units (catechin (C), epicatechin $(E C)$, gallocatechin (GC), epigallocatechin (EGC)) and their corresponding extension units (i.e. BM-adducts) were corrected relative to taxifolin at $280 \mathrm{~nm}$ : they were integrated and quantified using molar response factors relative to taxifolin according to Gea et al. (2011). Molar response factors for galloylated flavan-3-ols were calculated using commercially available standards: 0.72 for gallocatechin-3-O-gallate (GCg) and epigallocatechin-3-O-gallate (EGCg); 1.01 for catechin-3-O-gallate (Cg) and epicatechin-3-O-gallate (ECg). The same response factors were used for their corresponding benzyl mercaptan adducts (Meagher et al., 2005). This provided information on PA composition in terms of \% terminal and \% extension flavan-3-ol units (molar percentages); it also allowed calculation of the mean degree of polymerisation (mDP), the percentage of procyanidins (PC) and prodelphinidins (PD), and of cis- and trans-flavan-3-ols in the PA (Gea et al., 2011). The molar percentage of galloylated flavan-3-ols ( $\mathrm{Xg} \%$ ) was calculated as follows (Equation 1):

$\frac{\Sigma \text { Corrected areas of galloylated flavan }-3-\text { ols }}{\Sigma \text { Corrected areas of all flavan }-3-\text { ols }} \times 100$

Where for each of the different flavan-3-ols, corrected areas are calculated as follows:

Corrected area of flavan $-3-o l=\frac{\text { Area of flavan }-3-o l}{\text { Response factor }}$ 
Equations for calculating extractable PA (ePA), unextractable PA (uPA), mDP, percentages of PC and PD and of cis- and trans-flavan-3-ols are given in the Supplementary Section.

\section{Statistical analysis of PA contents and compositions}

Differences between PA parameters (content, mDP, PC or PD, cis or trans flavan-3ols, terminal and extension units) for the in situ PA, extractable PA and unextractable PA and the three PA fractions were assessed by a one-way analysis of variance (ANOVA) and a $T$-test for a two-pair comparison followed by Bonferroni hoc post test. $P$ values of $<0.05$ were considered significant. All analysis performed by Systat 9 (SPSS Ltd).

\subsubsection{NMR analysis}

The F2-fraction was dissolved in 4:1 DMSO- $d_{6} /$ pyridine- $d_{5}$ and transferred to a $5 \mathrm{~mm}$ NMR tube. ${ }^{1} \mathrm{H}-{ }^{13} \mathrm{C}$ correlation 2D NMR (HSQC) spectra were recorded at $27^{\circ} \mathrm{C}$ on a Bruker Avance III $500\left({ }^{1} \mathrm{H} 500.13 \mathrm{MHz},{ }^{13} \mathrm{C} 125.76 \mathrm{MHz}\right)$ instrument equipped with TopSpin 2.4 software and a $5-\mathrm{mm} \mathrm{BBI}{ }^{1} \mathrm{H} /{ }^{13} \mathrm{C}$ gradient probe (Bruker, Coventry, U.K.) (Zeller et al., 2015). Spectral resonances were referenced to the residual signals of DMSO-d 6 (2.49 ppm for ${ }^{1} \mathrm{H}$ and 39.5 ppm for ${ }^{13} \mathrm{C}$ spectra). For ${ }^{1} \mathrm{H}^{-13} \mathrm{C}$ HSQC experiments, spectra were obtained using 36 scans.

\subsubsection{Anthelmintic activity}

All animal experimentation was approved and carried out according to the guidelines of the Danish Animal Experimentation Inspectorate (Licence number 2010/5611914). Assessment of activity against $A$. suum was carried out as described 
previously (Williams et al., 2014). Briefly, L3 were obtained by in vitro hatching of fully embryonated eggs, and L4 were isolated from the small intestine of donor pigs 12 days after infection with 10,000 eggs given per os. Inhibition of L3 migratory ability was quantified using a modified agar migration inhibition assay, based on the method first described by Han et al. (2000). Fractions (at concentrations decreasing 2-fold from $500 \mu \mathrm{g} / \mathrm{ml}$ to $32.5 \mu \mathrm{g} / \mathrm{ml}$ ) were dissolved in culture media (RPMl 1640 supplemented with $2 \mathrm{mM} \mathrm{L-glutamine,} 100 \mu \mathrm{g} / \mathrm{ml}$ streptomycin and $100 \mathrm{U} / \mathrm{ml}$ penicillin), added to 48-well tissue culture plates and then 100 L3 were added to the wells containing either the fractions or culture media only. After overnight incubation at $37^{\circ} \mathrm{C}$, an equal volume of $1.6 \%$ agar $\left(45^{\circ} \mathrm{C}\right)$ was mixed into each well, resulting in a final agar concentration of $0.8 \%$. The agar was allowed to set and then fresh culture media was added on top of the agar. The plates were returned to the incubator overnight. The medium was then collected from the top of the agar in each well, and the number of L3 that migrated from the agar was quantified by light microscopy. Inhibition of migration was expressed as a percentage relative to the number of $L 3$ that migrated in the wells containing only culture media.

Effects against L4 stages were assessed by twice-daily monitoring the motility of worms exposed to varying concentrations of shea PA fractions over five days, by a single observer using a motility scoring system as described (Williams et al. 2014) where 5 is fully motile and 0 is motionless. Each analysis was based on fraction concentration and no adjustments were made for PA concentrations.

\section{Statistical analysis of anthelmintic activity}

The effects of concentration and fraction (F1, F2 or F3) on L3 migration inhibition were assessed by two-way ANOVA. Further, EC $_{50}$ values were calculated by non- 
linear regression, and differences between $\mathrm{EC}_{50}$ values for the three fractions were assessed by extra-sum-of-squares F-test. For the L4 motility inhibition assay, differences in the time taken (hours) for larvae to register a motility score of zero was assessed between concentrations of each fraction, and between different fractions at a concentration of $0.5 \mathrm{mg} / \mathrm{ml}$, by the Mantel-Cox test. The analyses were performed using Graphpad Prism (v6.00, GraphPad Software, La Jolla, California), and $P$ values of $<0.05$ were considered significant.

\section{Acknowledgements}

Financial support was provided by the European Commission (Marie Curie Initial Training Network, PITN-GA-2011-289377, "LegumePlus") and the Danish Council for Independent Research (Technology and Production Sciences, Grant \# 12-126630). The authors would to thank Chris Drake, Honorata Ropiak and Christos Fryganas for their support in the laboratory. 
Table 1: The composition of proanthocyanidins (PA) in whole shea meal (in situ PA), extract (extractable PA) and residue (unextractable PA) in terms of PA content, mean degree of polymerisation (mDP), molar percentages (\%) of procyanidins (PC) and prodelphinidins (PD), of cis- and trans-flavan-3-ols and of galloylated flavan-3-ols (Xg) (SD in parentheses; $n=3$ ).

\begin{tabular}{lccccccc}
\hline Proanthocyanidins & PA content $\$$ & mDP & $\%$ PC & \% PD & \% cis & $\%$ trans & $\%$ Xg \\
\hline In situ PA & $3.9(0.1)^{\mathrm{a}}$ & $8.5(0.9)^{\mathrm{b}}$ & $30.8(1.3)^{\mathrm{b}}$ & $69.2(1.2)^{\mathrm{b}}$ & $59.7(0.1)^{\mathrm{c}}$ & $40.3(0.1)^{\mathrm{a}}$ & $32.2(0.2)^{\mathrm{b}}$ \\
Extractable PA & $3.1(0.1)^{\mathrm{b}}$ & $4.1(0.1)^{\mathrm{c}}$ & $26.6(0.3)^{\mathrm{c}}$ & $73.4(0.2)^{\mathrm{a}}$ & $60.6(0.1)^{\mathrm{b}}$ & $39.4(0.1)^{\mathrm{b}}$ & $37.7(0.3)^{\mathrm{a}}$ \\
Unextractable PA & $2.1(0.1)^{\mathrm{c}}$ & $13.8(0.4)^{\mathrm{a}}$ & $34.1(0.6)^{\mathrm{a}}$ & $65.9(0.6)^{\mathrm{c}}$ & $61.3(0.6)^{\mathrm{a}}$ & $38.7(0.6)^{\mathrm{c}}$ & $31.6(0.4)^{\mathrm{c}}$
\end{tabular}

$\S$ in $\mathrm{g} / 100 \mathrm{~g}$ of meal on DW basis. (DW: dry weight).

PC include EC, C, ECg and Cg flavan-3-ol subunits; PD include EGC, GC, EGCg and GCg flavan-3-ol subunits.

Means followed by different letters within columns are statistically different $(P<0.001)$. 
Table 2: Flavan-3-ol composition of proanthocyanidins (PA) in whole shea meal (in situ PA), extract (extractable PA) and residue (unextractable PA) in terminal and extension units (relative molar percentages; SD in parentheses; $n=3$ ).

\begin{tabular}{|c|c|c|c|c|c|c|c|c|c|c|c|c|c|c|}
\hline \multirow[b]{2}{*}{ Proanthocyanidins } & \multicolumn{6}{|c|}{ Terminal units (\%) } & \multicolumn{8}{|c|}{ Extension units (\%) } \\
\hline & GC & EGC & $\mathrm{GCg}$ & $\mathrm{EGCg}$ & $C$ & $\mathrm{ECg}$ & $\mathrm{GC}$ & EGC & $\mathrm{GCg}$ & EGCg & $C$ & EC & $\mathrm{Cg}$ & $\mathrm{ECg}$ \\
\hline \multirow[t]{2}{*}{ In situ PA } & $0.6^{b}$ & $2.5^{\mathrm{b}}$ & $1.2^{b}$ & $5.0^{b}$ & $0.7^{\mathrm{b}}$ & $1.9^{a}$ & $27.5^{\mathrm{a}}$ & $14.4^{\mathrm{a}}$ & $5.2^{b}$ & $12.8^{b}$ & $4.4^{b}$ & $17.7^{b}$ & $0.6^{a}$ & $5.5^{b}$ \\
\hline & $(0.1)$ & $(0.2)$ & $(0.1)$ & $(1.6)$ & $(0.1)$ & $(0.1)$ & $(0.2)$ & $(0.7)$ & $(0.3)$ & $(0.7)$ & $(0.1)$ & $(0.6)$ & $(0.1)$ & $(0.3)$ \\
\hline \multirow[t]{2}{*}{ Extractable PA } & $6.4^{\mathrm{a}}$ & $5.5^{\mathrm{a}}$ & $1.9^{a}$ & $7.6^{\mathrm{a}}$ & $1.4^{\mathrm{a}}$ & $1.8^{\mathrm{a}}$ & $20.0^{b}$ & $11.9^{b}$ & $5.7^{a}$ & $14.5^{\mathrm{a}}$ & $3.5^{c}$ & $13.6^{c}$ & $0.5^{a}$ & $5.8^{b}$ \\
\hline & $(0.1)$ & $(0.5)$ & $(0.1)$ & $(0.1)$ & $(0.1)$ & $(0.1)$ & $(0.4)$ & $(0.3)$ & $(0.1)$ & $(0.3)$ & $(0.1)$ & $(0.2)$ & $(0.1)$ & $(0.1)$ \\
\hline \multirow[t]{2}{*}{ Unextractable PA } & $0.4^{\mathrm{c}}$ & $0.9^{c}$ & $0.7^{c}$ & $3.6^{c}$ & $0.4^{c}$ & $1.2^{b}$ & $26.9^{a}$ & $14.4^{\mathrm{a}}$ & $4.9^{c}$ & $14.0^{\mathrm{a}}$ & $4.8^{a}$ & $20.4^{a}$ & $0.6^{a}$ & $6.7^{a}$ \\
\hline & $(0.1)$ & $(0.1)$ & $(0.1)$ & $(0.1)$ & $(0.1)$ & $(0.1)$ & $(0.7)$ & $(0.4)$ & $(0.1)$ & $(0.4)$ & $(0.1)$ & $(0.5)$ & $(0.1)$ & $(0.2)$ \\
\hline
\end{tabular}

Note: The sum of terminal and extension units adds up to $100 \%$ (see Supplementary Section for a different presentation of these data, where terminal flavan-3-ols subunits and extension flavan-3-ols are considered separately, so that each group adds up to $100 \%)$. Means followed by different letters within columns are statistically different $(P<0.001)$. 
Table 3: Concentrations of free flavan-3-ols in whole shea meal, acetone/water extract and in Sephadex LH-20 eluted proanthocyanidin (PA) fractions (SD in parentheses; $n=3)$.

\begin{tabular}{|c|c|c|c|c|c|c|}
\hline Samples & $\mathrm{GC}$ & EGC & $\mathrm{GCg}$ & $\mathrm{EGCg}$ & $\mathrm{C}$ & $\mathrm{ECg}$ \\
\hline Whole shea meal§ & nd & nd & $0.1(0.1)^{b}$ & $0.1(0.1)^{b}$ & nd & $0.1(0.1)^{b}$ \\
\hline Acetone/water extract ${ }^{\dagger}$ & $1.7(0.1)$ & $1.6(0.6)$ & $0.6(0.2)^{a}$ & $2.3(0.4)^{\mathrm{a}}$ & $0.7(0.2)$ & $0.6(0.1)^{a}$ \\
\hline PA F1-fraction $\#$ & $3.0(0.2)$ & $2.5(0.3)$ & $0.6(0.1)^{\mathrm{c}}$ & $3.1(0.2)^{d}$ & $0.6(0.1)$ & $0.6(0.1)^{d}$ \\
\hline PA F2-fraction $\#$ & nd & nd & $0.4(0.1)^{d}$ & $3.9(0.5)^{c}$ & nd & $1.5(0.1)^{\mathrm{c}}$ \\
\hline PA F3-fraction $\#$ & nd & nd & nd & nd & nd & nd \\
\hline
\end{tabular}

$\S$ in $\mathrm{g} / 100 \mathrm{~g}$ of meal; ${ }^{\dagger}$ in $\mathrm{g} / 100 \mathrm{~g}$ of extract; $\#$ in $\mathrm{g} / 100 \mathrm{~g}$ of fraction (all on dry weight basis); nd: none detected

Means followed by different letters within columns are statistically different: ${ }^{a, b}$ ) comparisons apply to whole meal versus acetone/water extract $(P<0.001)$; $\left.{ }^{\mathrm{c}, \mathrm{d}}\right)$ comparisons apply to the PA fractions $(P<0.005)$. 
Table 4. Composition of proanthocyanidin (PA) fractions in terms of PA content ( $\mathrm{g} / 100 \mathrm{~g}$ fraction on dry weight basis), mean degree of polymerisation (mDP), molar percentage (\%) of procyanidins (PC) and prodelphinidins (PD), of cis- and trans-flavan-3-ols and of galloylated flavan-3-ols $(\mathrm{Xg})(\mathrm{SD}$ in parentheses; $\mathrm{n}=3$ ).

\begin{tabular}{lccccccc}
\hline PA fractions & PA content & mDP & $\%$ PC & $\%$ PD & \% cis & $\%$ trans & $\%$ Xg \\
\hline F1-fraction & $33.0(0.6)^{\mathrm{b}}$ & $2.2(0.1)^{\mathrm{c}}$ & $23.7(0.1)^{\mathrm{b}}$ & $76.3(0.1)^{\mathrm{a}}$ & $58.6(0.3)^{\mathrm{c}}$ & $41.4(0.3)^{\mathrm{a}}$ & $28.8(0.1)^{\mathrm{c}}$ \\
F2-fraction & $44.9(0.8)^{\mathrm{a}}$ & $4.1(0.1)^{\mathrm{b}}$ & $27.5(0.1)^{\mathrm{a}}$ & $72.5(0.1)^{\mathrm{b}}$ & $59.8(0.1)^{\mathrm{b}}$ & $40.2(0.1)^{\mathrm{b}}$ & $46.1(0.2)^{\mathrm{a}}$ \\
F3-fraction & $33.5(1.5)^{\mathrm{b}}$ & $7.7(0.2)^{\mathrm{a}}$ & $26.8(0.8)^{\mathrm{a}}$ & $73.2(0.8)^{\mathrm{b}}$ & $75.5(3.9)^{\mathrm{a}}$ & $24.5(3.9)^{\mathrm{c}}$ & $37.5(1.6)^{\mathrm{b}}$
\end{tabular}

PC include EC, C, ECg and Cg flavan-3-ol subunits; PD include EGC, GC, EGCg and GCg flavan-3-ol subunits.

Means followed by different letters within columns are statistically different $(P<0.001)$. 
Table 5: Composition of flavan-3-ol terminal and extension units in proanthocyanidin (PA) fractions (relative molar percentages; SD in parentheses; $n=3$ ).

\begin{tabular}{|c|c|c|c|c|c|c|c|c|c|c|c|c|c|c|}
\hline \multirow[b]{2}{*}{ PA fractions } & \multicolumn{6}{|c|}{ Terminal units (\%) } & \multicolumn{8}{|c|}{ Extension units (\%) } \\
\hline & $G C$ & EGC & $\mathrm{GCg}$ & $\mathrm{EGCg}$ & C & $\mathrm{ECg}$ & $\mathrm{GC}$ & EGC & GCg & $\mathrm{EGCg}$ & C & EC & $\mathrm{Cg}$ & $\mathrm{ECg}$ \\
\hline \multirow[t]{2}{*}{ F1-fraction } & $16.1^{a}$ & $10.8^{\mathrm{a}}$ & $1.5^{\mathrm{c}}$ & $10.7^{a}$ & $3.4^{\mathrm{a}}$ & $2.2^{\mathrm{b}}$ & $11.9^{\mathrm{b}}$ & $13.8^{\mathrm{a}}$ & $4.3^{\mathrm{b}}$ & $7.1^{\mathrm{c}}$ & $3.8^{a}$ & $11.4^{\mathrm{b}}$ & $0.4^{\mathrm{c}}$ & $2.6^{c}$ \\
\hline & $(0.1)$ & $(0.1)$ & $(0.0)$ & $(0.1)$ & $(0.0)$ & $(0.0)$ & $(0.5)$ & $(0.3)$ & $(0.1)$ & $(0.0)$ & $(0.0)$ & $(0.0)$ & $(0.0)$ & $(0.0)$ \\
\hline \multirow[t]{2}{*}{ F2-fraction } & $4.1^{\mathrm{b}}$ & $2.5^{\mathrm{b}}$ & $3.8^{\mathrm{a}}$ & $9.8^{b}$ & $1.1^{\mathrm{b}}$ & $2.9^{a}$ & $20.7^{a}$ & $9.4^{b}$ & $6.1^{\mathrm{a}}$ & $16.0^{\mathrm{b}}$ & $3.5^{\mathrm{b}}$ & $12.6^{\mathrm{a}}$ & $0.8^{\mathrm{a}}$ & $6.6^{b}$ \\
\hline & $(0.1)$ & $(0.1)$ & $(0.0)$ & $(0.1)$ & $(0.0)$ & $(0.0)$ & $(0.2)$ & $(0.3)$ & $(0.0)$ & $(0.1)$ & $(0.1)$ & $(0.0)$ & $(0.0)$ & $(0.1)$ \\
\hline \multirow[t]{2}{*}{ F3-fraction } & $2.5^{c}$ & $1.6^{c}$ & $1.9^{b}$ & $5.3^{c}$ & $0.7^{c}$ & $1.0^{\mathrm{C}}$ & $11.9^{b}$ & $2.9^{c}$ & $2.9^{c}$ & $18.1^{\mathrm{a}}$ & $3.8^{a}$ & $13.0^{\mathrm{a}}$ & $0.6^{\mathrm{b}}$ & $7.6^{a}$ \\
\hline & $(0.2)$ & $(0.1)$ & $(0.0)$ & $(0.3)$ & $(0.3)$ & $(0.6)$ & $(4.9)$ & (2.3) & $(0.2)$ & $(1.2)$ & $(0.1)$ & $(0.8)$ & $(0.1)$ & $(0.5)$ \\
\hline
\end{tabular}

Note: The sum of terminal and extension units adds up to $100 \%$ (See Supplementary Section for a different presentation of these data, where the terminal flavan-3-ols subunits and the extension flavan-3-ols are considered separately, so that each group adds up to $100 \%)$. Means followed by different letters within columns are statistically different $(P<0.009)$. 


\section{Figure legends}

Figure 1. Examples of galloylated flavan-3-ols and a galloylated PA trimer.

Figure 2. Example of an HPLC chromatogram after thiolysis of galloylated proanthocyanidins (F2-fraction) isolated from shea meal: 1, GC; 2, EGC; 3, C; 4, EGCg; 5, GCg; 6, ECg; 7; IS (taxifolin); 8, trans-GC-BM; 9, cis-GC-BM; 10, EGC-BM; 11, GCg-BM; 12 Cg-BM; 13, EGCg-BM; 14 cis C-BM; 15, EC-BM; 16, ECg-BM, BM: benzyl mercaptan (see Experimental Section for details of abbreviations).

Figure 3. Inhibition of migration of Ascaris suum L3 by shea proanthocyanidin fractions (results are the mean of two independent experiments, each performed in triplicate).

Figure 4. Inhibition of motility of Ascaris suum L4 by shea proanthocyanidin fractions in three dilutions, A) F1-fraction, B) F2-fraction, C) F3-fraction (results are a single experiment performed in triplicate). 


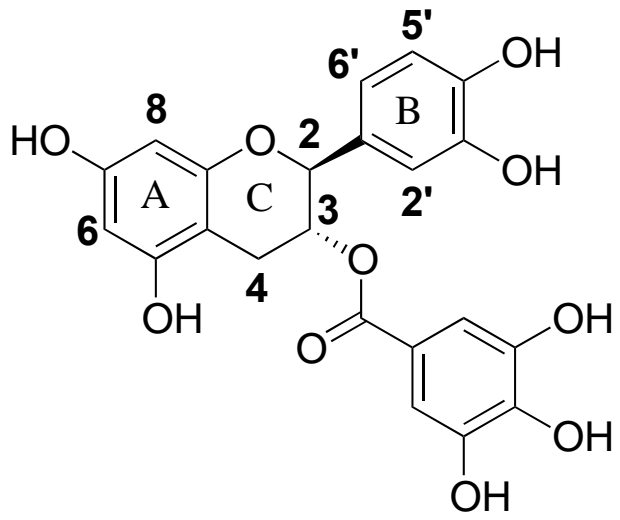

(-)-Catechin-O-gallate (a trans-flavan-3-ol)<smiles>O=C(O[C@H]1Cc2c(O)cc(O)cc2O[C@@H]1c1cc(O)c(O)c(O)c1)c1cc(O)c(O)c(O)c1</smiles>

(-)-Gallocatechin-O-gallate (a trans-flavan-3-ol)<smiles>O=C(O[C@H]1Cc2c(O)cc(O)cc2O[C@@H]1c1ccc(O)c(O)c1)c1cc(O)c(O)c(O)c1</smiles>

(-)-Epicatechin-O-gallate (a cis-flavan-3-ol)<smiles>O=C(O[C@H]1Cc2c(O)cc(O)cc2O[C@@H]1c1cc(O)c(O)c(O)c1)c1cc(O)c(O)c(O)c1</smiles>

(-)-Epigallocatechin-O-gallate (a cis-flavan-3-ol)

Figure 1A 


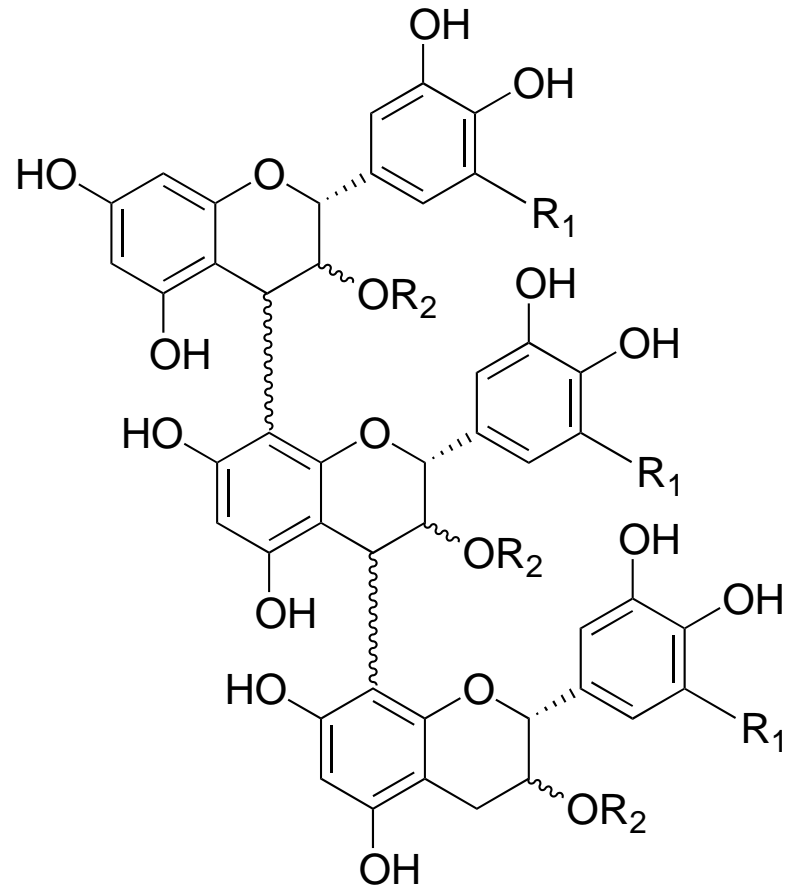

Figure 1B<smiles>CC(=O)c1cc(O)c(O)c(O)c1</smiles>

Galloyl group

$\mathrm{R}_{1}=\mathrm{H}$ or $\mathrm{OH}$

$\mathrm{R}_{2}=\mathrm{H}$ or galloyl- 


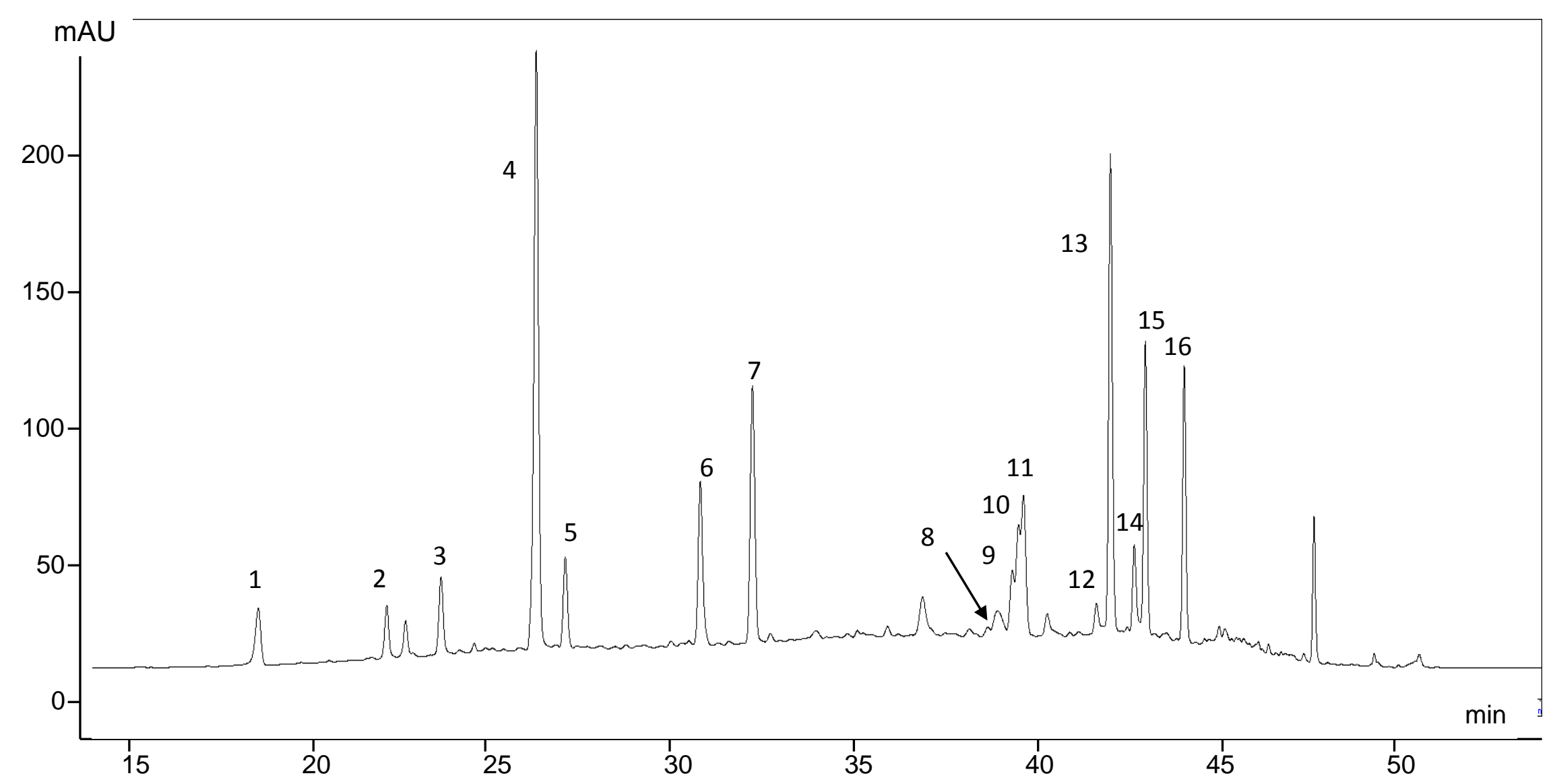

Figure 2 


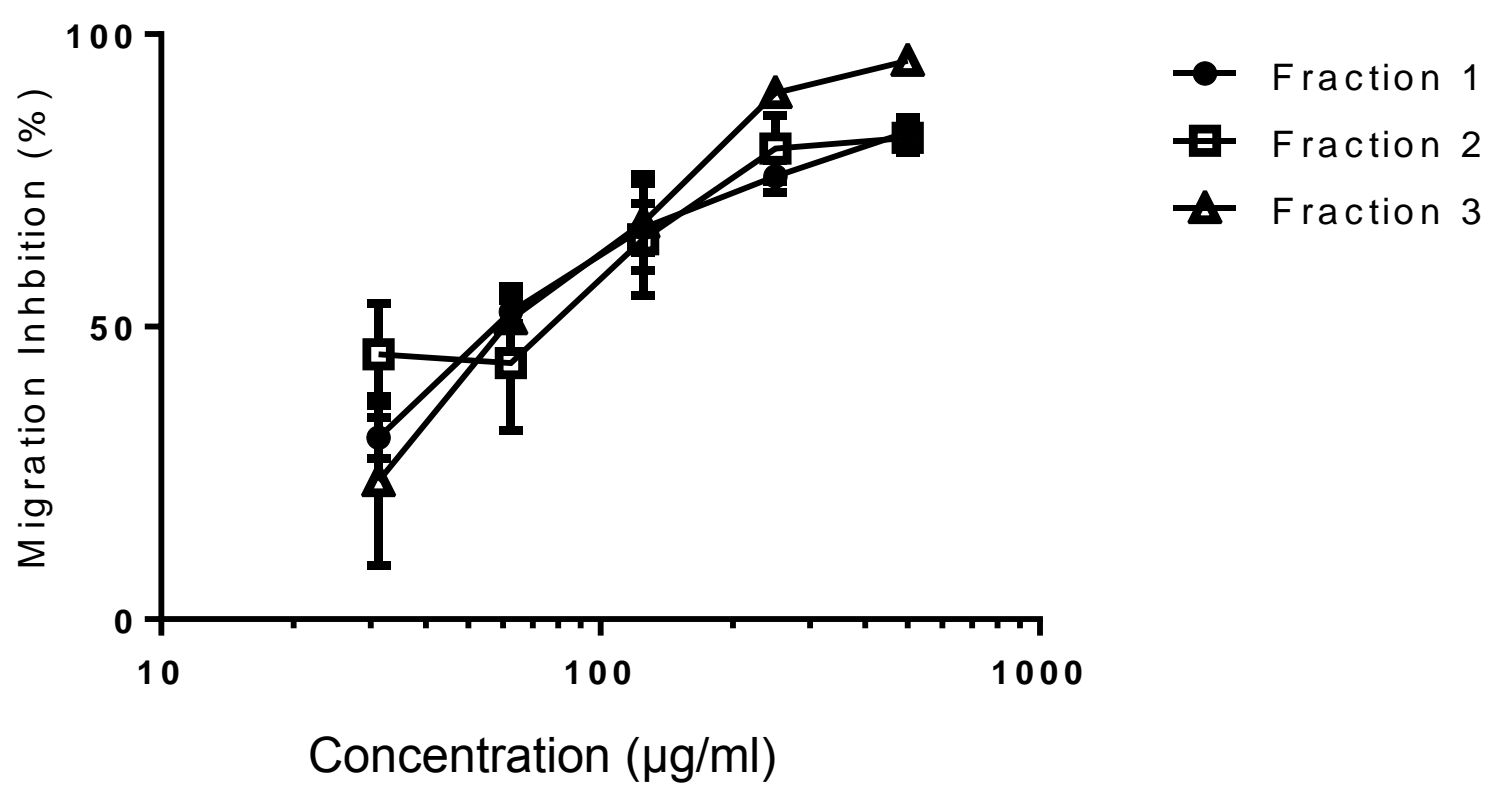

Figure 3 

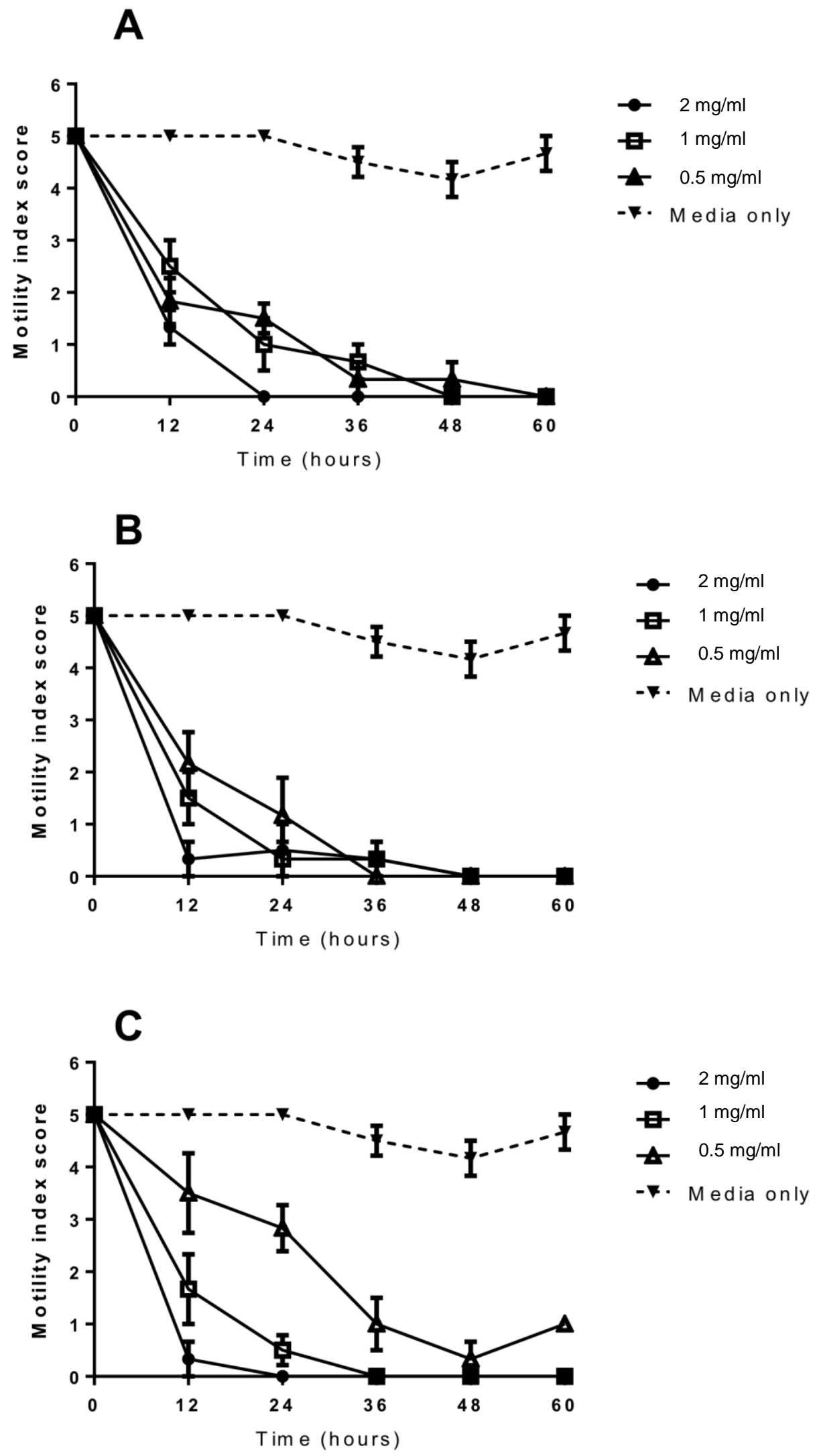

Figure 4 


\section{References}

Alemede, I., Ogunbajo, S., 2013. Effect of feeding varying levels of sheanut meal (Vitellaria paradoxa) on haematological parameters, diseases and mortality of weaner rabbits (Oryctolagus cunniculus). Agric. Biol. J. N. Am. 4, 78-83.

Ansah, T., Mensah, J., Bayong, P., Deku, G., Karikari, P. K., 2011. Effect of dietary shea nut cake on the growth and blood parameters of rabbits. Anim. Prod. Res. Adv. 7, 81-86.

Atuathene, C. C., Donkoh, A., Asante, F., 1998. Value of sheanut cake as a dietary ingredient for broiler chickens. Anim. Feed Sci. Tech. 72, 133-142.

Bancroft, A. J., Hayes, K. S., Grencis, R. K., 2012. Life on the edge: the balance between macrofauna, microflora and host. immunity. Trends Parasitol. 28, 93-98.

Bhatta, R., Mani, S., Baruah, L., Sampath, K. T., 2012. Phenolic composition, fermentation profile, protozoa population and methane production from sheanut (Butryospermum parkii) byproducts in vitro. Asian-Aust. J. Anim. Sci. 25, 1389-1394.

Brunet, S., Hoste, H., 2006. Monomers of condensed tannins affect the larval exsheathment of parasitic nematodes of ruminants. J. Agric. Food Chem. 54, 74817487.

Cousins, B. W., Tanksley, T. D., Knabe, D .A., Zebrowska, T., 1981. Nutrient 
digestibility and performance of pigs fed sorghums varying in tannin concentration, J. Anim. Sci. 53, $1524-1537$.

Dei, H., Rose, S., Mackenzie, A., 2007. Shea nut (Vitellaria paradoxa) meal as a feed ingredient for poultry. World Poultry Sci. J. 63, 611-624.

Dei, H. K., Rose, S. P., Mackenzie, A. M., 2008. Effects of fungal (Aspergillus niger or Ceriporiopsis subvermispora) fermentation on the nutritive value of shea nut (Vitellaria paradoxa) meal for broiler chicks. Br. Poult. Sci. 49, 360-7.

Dobreva, M. A., Green, R. J., Mueller-Harvey, I., Salminen, J-P., Howlin, B. J., Frazier, R. A., 2014. Size and molecular flexibility affect the binding of ellagitannins to bovine serum albumin. J. Agric. Food Chem. 62, 9186-9194.

Foo, L. Y., Lu, Y. O.-P., Molan, A. L., Woodfield, D. R., McNabb, W. C., 2000. The phenols and prodelphinidins of white clover flowers. Phytochemistry 54, 539-548.

Frazier, R.A., Deaville, E.R., Green, R.J., Willoughby, I., Stringano, E., Plant, J., Mueller-Harvey, I. 2010. Interactions of tea tannins and condensed tannins with proteins. J. Pharm. Biomed. Anal. 51, 490-495.

Gea, A., Stringano, E., Brown, R. H., Mueller-Harvey, I., 2011. In situ analysis and structural elucidation of sainfoin (Onobrychis viciifolia) tannins for high-throughput germplasm screening. J. Agric. Food Chem. 59, 495-503. 
Grabber, J. H., Zeller, W. E., Mueller-Harvey, I., 2013. Acetone enhances the direct analysis of procyanidin- and prodelphinidin-based condensed tannins in Lotus species by the butanol-HCl-iron assay. J. Agric. Food Chem. 61, 2669-2678.

Hale, O. M., Stewart, T. B., Marti, O. G., 1985. Influence of an experimental infection of Ascaris suum on performance of pigs. J. Anim. Sci. 60, 220-225.

Hall, J. B., Aebischer, D. P., Tomlinson, H. F., Osei-Amaning, E., Hindle, J. R. Vitellaria paradoxa: A monograph. School of Agricultural and Forest Sciences, University of Wales: Bangor, U.K., 1996.

Han, Q., Eriksen, L., Boes, J., Nansen, P., 2000. Effects of bile on the in vitro hatching, exsheathment, and migration of Ascaris suum larvae. Parasitol. Res. 86, 630-633.

Hoste, H., Martinez-Ortiz-De-Montellano, C., Manolarakia, F., Brunet, S., OjedaRobertos, N., Fourquaux, I., Torres-Acosta, J. F. J., Sandoval-Castro, C. A., 2012. Direct and indirect effects of bioactive tannin-rich tropical and temperate legumes against nematode infections. Vet. Parasitol. 186, 18-27.

Hoste, H., Torres-Acosta, J. F. J., Sandoval-Castro, C. A., Mueller-Harvey, I., Sotiraki, S., Louvandini, H., Thamsborg, S. M., Terrill, T. H., 2015. Tannin containing legumes as a model for nutraceuticals against digestive parasites in livestock. Vet. Parasitol. 212, 5-17 
Kamiya, K., Watanabe, C., Endang, H., Umar, M., Satake, T., 2001. Studies on the constituents of bark of Parameria laevigata Moldenke. Chem. Pharm. Bull. 49, 551557.

Kumar, M. K., Kalyani, P., 2015. Effect of sheanut cake based complete diet on mineral balance in graded murrah buffalo calves. Int. J. Pharma Bio Sci. 3, 459-464. Parasitol. 212, 5-17.

Li, C., Leverence, R., Trombley, J. D., Xu, S., Yang, J., Tian, Y., Reed, J. D., Hagerman, A. E. 2010. High molecular weight persimmon (Diospyros kaki L.) proanthocyanidin: A highly galloylated, A-linked tannin with an unusual flavonol terminal unit, myricetin. J. Agric. Food Chem. 58, 9033-9042.

Maranz, S., Wiesman, Z., Garti, N., 2003. Phenolic constituents of shea (Vitellaria paradoxa) kernels. J. Agric. Food Chem. 51, 6268-6273.

Meagher, L.P., Spencer, P., Lane, G., A., Sivakumaran, S., Fraser, K., 2005. What do green tea, grapes seeds, and docks have in common? Chem. New Zealand 1, 69.

Mitaru, B. N., Reichert, R., Blair, R., 1984. The binding of dietary protein by sorghum tannins in the digestive tract of pigs. J. Nutr. 114, 1787-1796.

Molan, A. L., Meagher, L. P., Spencer, P. A., Sivakumaran, S., 2003. Effect of flavan- 
3-ols on in vitro egg hatching, larval development and viability of infective larvae of Trichostrongylus colubriformis. Int. J. Parasitol. 33, 1691-1698.

Molan, A. L., Sivakumaran, S., Spencer, P. A., Meagher, L. P., 2004. Green tea flavan-3-ols and oligomeric proanthocyanidins inhibit the motility of infective larvae of Teladorsagia circumcincta and Trichostrongylus colubriformis in vitro. Res. Vet. Sci. 77, 239-243.

Mueller-Harvey, I., 2006. Unravelling the conundrum of tannins in animal nutrition and health. J. Sci. Food Agric. 86, 2010-2037.

Munir, S., Daood, S. S., Nimmo, W., Cunliffe, A. M., Gibbs, B. M., 2009. Thermal analysis and devolatilization kinetics of cotton stalk, sugar cane bagasse and shea meal under nitrogen and air atmospheres. Bioresource Technol. 100, 1413-1418.

Munir, S., Nimmo, W., Gibbs, B. M., 2010. Shea meal and cotton stalk as potential fuels for co-combustion with coal. Bioresource Technol. 101, 7614-7623.

Novobilský, A, Mueller-Harvey I, Thamsborg SM 2011. Condensed tannins act against cattle nematodes. Vet. Parasitol. 182, 213-220.

Ogunwande, I. A., Bello, M. O., Olawore, O. N., 2001. Phytochemical and antimicrobial studies on Butyrospermum paradoxum. Fitoterapia 72, 54-56. 
Porter, L. J., 1988. Flavans and Proanthocyanidins. In: The Flavonoids: Advances in Research since 1980 (J. B. Harborne, ed.), Chapman \& Hall, London, UK. p. 21-62.

Quainoo, A. K., Konadu, A., Kumi, M., 2015. The potential of shea nut shells in phytoremediation of heavy metals in contaminated soil using lettuce (Lactuca sativa) as a test crop. J. Bioremed. Biodeg. 6, 1-7.

Quijada J, Fryganas C, Ropiak HM, Ramsay A, Mueller-Harvey I, Hoste H. 2015. Anthelmintic activities against Haemonchus contortus or Trichostrongylus colubriformis from small ruminants are influenced by structural features of condensed tannins. J. Agric. Food Chem. 63, 6346-6354.

Sutherland, I. A., Leathwick, D. M., 2011. Anthelmintic resistance in nematode parasites of cattle: a global issue? Trends Parasitol. 27, 176-181.

Vlaminck, J., Dusseldorf, S., Heres, L., Geldhof, P., 2015. Serological examination of fattening pigs reveals associations between Ascaris suum, lung pathogens and technical performance parameters. Vet. Parasitol. 210, 151-158.

Williams, A. R., Fryganas, C., Ramsay, A., Mueller-Harvey, I., Thamsborg, S. M., 2014. Direct anthelmintic effects of condensed tannins from diverse plant sources against Ascaris suum. PLoS ONE. 9, 1-16.

Website 1:

http://www.unctad.info/upload/Infocomm/Docs/Karite/Market\%20and\%20Technical\% 
20Survey\%20Fintrac.pdf (accessed 10 August 2015).

Website 2: http://ec.europa.eu/research/bioeconomy/policy/strategy_en.htm (accessed 11 August 2015).

Zeller, W.E., Ramsay, A., Ropiak, H.M., Fryganas, C., Mueller-Harvey, I., Brown, R.H., Drake, C., Grabber, J.H. 2015. ${ }^{1} \mathrm{H}^{-13} \mathrm{C}$ HSQC NMR spectroscopy for estimating procyanidin/prodelphinidin and cis/trans flavanol ratios of condensed tannin fractions: correlation with thiolysis. J. Agric. Food Chem.63, 1967-1973.

Zhang, J., Kurita, M., Shinozaki, T., Ukiya, M., Yasukawa, K., Shimizu, N., Tokuda, H., Masters, E.T., Akihisa, M., Akihisa, T., 2014. Triterpene glycosides and other polar constituents of shea (Vitellaria paradoxa) kernels and their bioactivities. Phytochemistry 108, 157-170. 